\title{
Finite element simulation of magnesium alloy sheet forming at elevated temperatures
}

\author{
Hariharasudhan Palaniswamy, Gracious Ngaile, Taylan Altan* \\ ERC for Net Shape Manufacturing, The Ohio State University, 339 Baker Systems, 1971 Neil Ave., Columbus, OH 43210, USA
}

\begin{abstract}
The use of lightweight magnesium $(\mathrm{Mg})$ alloy offers significant potential to improve automotive fuel efficiency. However, the application of formed magnesium alloy components in auto-body structures is restricted due to this material's low formability at room temperature and lack of knowledge for processing magnesium alloys at elevated temperature. In this study, non-isothermal finite element (FE) simulation has been conducted for forming round cups and rectangular pans from Mg alloy AZ31B sheet at elevated temperatures. The results were compared with experiments, conducted at the Technical University, Hanover. Simulation and experiments predicted increase in limiting draw ratio (LDR) with increase in temperature. Maximum LDR was obtained at the forming temperature of $200^{\circ} \mathrm{C}$. FE simulation results agreed well with experimental observations.
\end{abstract}

(C) 2003 Elsevier B.V. All rights reserved.

Keywords: Finite element; Magnesium; Warm sheet forming

\section{Introduction}

Weight reduction while maintaining functional requirements is one of the major goals of engineering design and manufacturing so that materials, energy, and costs are saved and damage to the environment is reduced. $\mathrm{Mg}$ alloys offer great potential to reduce weight by displacing the most commonly used materials, i.e. steel and polymers, because of their low density (78\% lighter per unit volume than steel). Presently Mg alloy parts, used in structural applications, are mainly produced by die casting and often they do not meet safety requirements. A promising alternative can be seen in parts manufactured by forming. Formed $\mathrm{Mg}$ alloy sheet has advantageous material properties and fine-grained structure without porosity and offers better mechanical properties than castings [1]. The use of conventional forming technology for $\mathrm{Mg}$ alloy sheet is restricted because of the low formability of $\mathrm{Mg}$ alloys at room temperature. However, $\mathrm{Mg}$ alloys show increased formability in the temperature range $200-300^{\circ} \mathrm{C}$. This is due to the activation of additional slip planes (pyramidal plane $\left.\left\langle\begin{array}{lllll}1 & 1 & 0 & 1\end{array}\right\rangle\right)$ in magnesium alloy's hexagonal closed packed structure [2-5].

Droder [6] conducted extensive experimental investigation on the forming properties of magnesium alloys, using

\footnotetext{
* Corresponding author.

E-mail address: altan.1@osu.edu (T. Altan).

URL: http://www.ercnsm.org.
}

$\mathrm{Mg}$ alloy sheet AZ31B in his experiments. He observed that round cups of $100 \mathrm{~mm}$ diameter were drawn to a maximum height of $120 \mathrm{~mm}$ (limiting draw ratio, LDR $=2.5$ ) at a forming temperature of $200^{\circ} \mathrm{C}$, while rectangular pans $(110 \mathrm{~mm} \times 220 \mathrm{~mm})$ could be drawn to a maximum height of $65 \mathrm{~mm}$ at $225^{\circ} \mathrm{C}$. Punch temperature during the process influenced the LDR. Maximum LDR was obtained when the punch was maintained at room temperature. Droder found that the blank holder force, required to suppress wrinkles in drawing, decreases with increase in forming temperature for both round and rectangular geometries. Doege et al. [7] reported that the formability of $\mathrm{Mg}$ alloys at elevated temperatures could be further increased by locally varying the temperature in the tool. A rectangular pan $(110 \mathrm{~mm} \times 220 \mathrm{~mm})$ was drawn to a depth of $98 \mathrm{~mm}$ by maintaining high temperature at tool corners and low temperature at straight edges. Thus, the better formability exhibited by $\mathrm{Mg}$ alloy sheet at high temperature could be exploited to form this material to manufacture lightweight components in the body and chassis of automobiles and in other structural applications.

Successful application of formed $\mathrm{Mg}$ alloys requires an economical manufacturing process. Optimal design of warm forming process for sheet metal requires critical consideration of: (a) material flow behavior of $\mathrm{Mg}$ alloy sheet at elevated temperature; (b) lubrication system at the tool/blank interface; (c) tool design with temperature control; and (d) warm forming process design, analysis and optimization using finite element $(\mathrm{FE})$ method. 
Droder [6] and Doege et al. [7] have extensively investigated the material properties of $\mathrm{Mg}$ alloy sheets, interface conditions and tool design for warm forming. The application of FEM for warm forming process design is in its early stage. Ghosh and Kikuchi [8] proposed a coupled thermo-mechanical FEM formulation for FE simulation of warm sheet forming process. Bolt et al. [9] applied coupled FEM for simulating the warm sheet forming process of aluminum alloys using the commercial code MARC. They concluded that, compared to experiments, numerical simulation results underestimate the punch load versus stroke.

In this study, DEFORM 2D and 3D, coupled thermoelastic-visco-plastic commercial FEM codes have been used to analyze warm forming of magnesium alloys. Forming operations for two shapes, a round cup and a rectangular pan were analyzed. Load-stroke curve, thickness distribution, and temperature distribution in the sheet obtained in experiments [6,7] were compared with FE simulation results for various forming temperatures.

\section{Warm forming of $\mathrm{Mg}$ alloy round cup}

\subsection{FE model}

FE simulations of round cup drawing at elevated temperatures were conducted for $\mathrm{Mg}$ alloy AZ31B. In these simulations, the geometry was modeled over a unit radian about the $Z$-axis due to the axisymmetric deformation mode (Fig. 1). The sheet was meshed with axisymmetric quadrilateral element with four elements along the thickness to capture the bending strains. These elements have both temperature and displacement as their degrees of freedom to predict both deformation and temperature variation during the process. The dies were considered rigid but non-isothermal. The inputs to the FE simulations are shown in Table 1.

The flow stress data for the blank material obtained by Droder [6] from tensile test, Figs. 2 and 3, was used in the

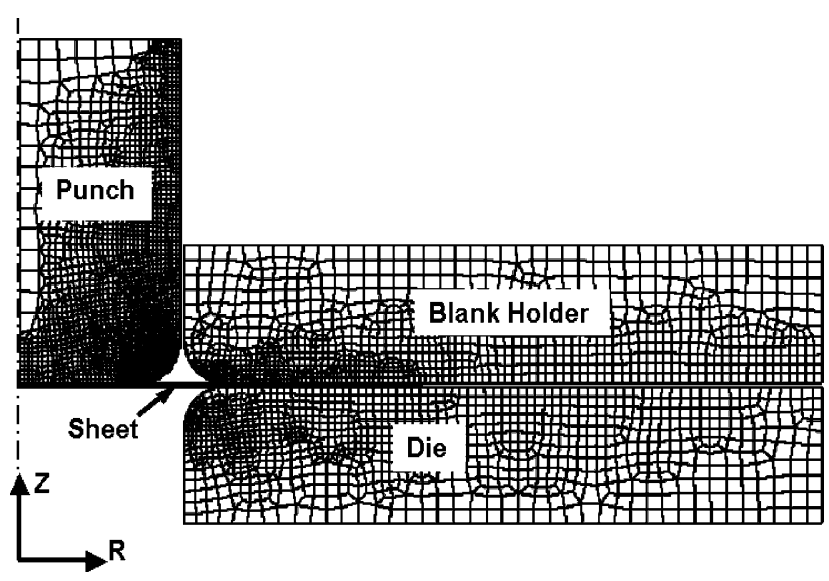

Fig. 1. FE model of the round cup warm sheet forming process in DEFORM 2D.
Table 1

Process parameters used in simulation

\begin{tabular}{|c|c|}
\hline \multicolumn{2}{|l|}{ Tooling setup } \\
\hline Punch diameter $(\mathrm{mm})$ & 100 \\
\hline Punch and die corner radius $(\mathrm{mm})$ & 12 \\
\hline Initial punch temperature $\left({ }^{\circ} \mathrm{C}\right)$ & 25 \\
\hline Blank material & AZ31B \\
\hline Thickness (mm) & 1.3 \\
\hline \multicolumn{2}{|l|}{ Mechanical properties } \\
\hline Young's modulus, $E(\mathrm{GPa})$ & 44.8 \\
\hline Poisson's ratio, $v$ & 0.35 \\
\hline Flow stress curve & Obtained from \\
\hline & $\begin{array}{l}\text { literature } \\
\text { (Figs. } 2 \text { and 3) }\end{array}$ \\
\hline Friction coefficient, $\mu$ & 0.10 \\
\hline \multicolumn{2}{|l|}{ Thermal properties } \\
\hline Thermal conductivity (sheet) $(\mathrm{N} / \mathrm{s} \mathrm{C})$ & 159 \\
\hline Heat capacity (sheet) $\left(\mathrm{N} / \mathrm{mm}^{2} \mathrm{C}\right)$ & 1.7675 \\
\hline Thermal conductivity (tool) $(\mathrm{N} / \mathrm{s} \mathrm{C})$ & 60.5 \\
\hline Heat capacity (tool) $\left(\mathrm{N} / \mathrm{mm}^{2} \mathrm{C}\right)$ & 3.41 \\
\hline Convection coefficient (N/s mm C) & 0.03 \\
\hline Interface heat transfer coefficient (N/s mm C) & 4.5 \\
\hline Factor to convert plastic deformation energy to heat & 0.95 \\
\hline
\end{tabular}

Material: AZ31B, Thickness: 1.3

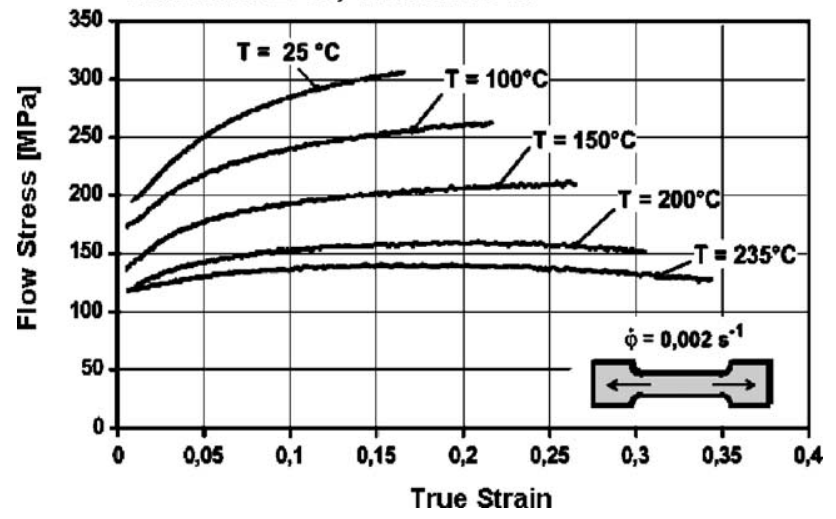

Fig. 2. Flow stress of magnesium alloy sheet AZ31B at different temperatures [6].

Material: AZ31B, Thickness: $1.3 \mathrm{~mm}$, Temperature: $200^{\circ} \mathrm{C}$

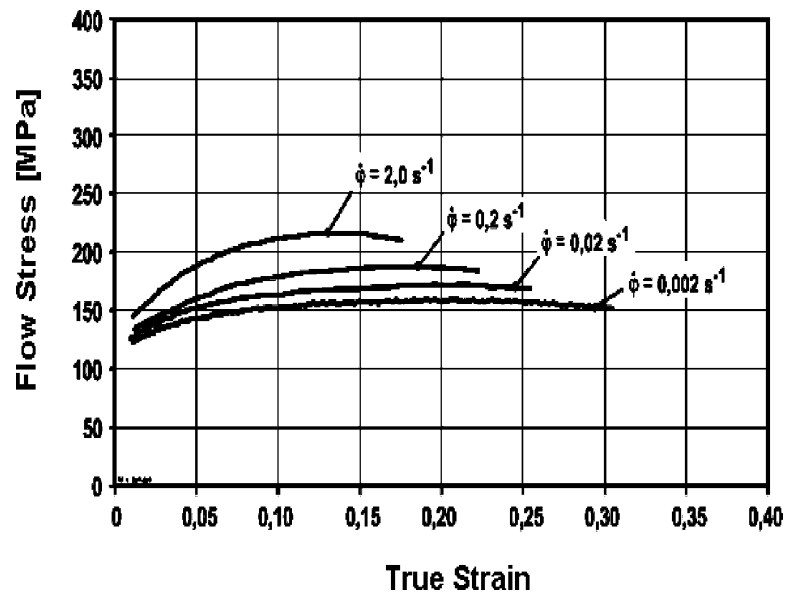

Fig. 3. Flow stress of magnesium alloy sheet AZ31B for different strain rates [6]. 
Table 2

Case study matrix from Droder [6]

\begin{tabular}{llll}
\hline Case studies & LDR & $\begin{array}{l}\text { Die, blank and } \\
\text { blank holder } \\
\text { temperature }\left({ }^{\circ} \mathrm{C}\right)\end{array}$ & $\begin{array}{l}\text { Initial blank } \\
\text { holder pressure } \\
(\mathrm{MPa})\end{array}$ \\
\hline A1 & 2.3 & 150 & 1.9 \\
A2 & 2.3 & 200 & 1.55 \\
A3 & 2.3 & 250 & 1.1 \\
A4 & 2.3 & 300 & 0.8 \\
\hline
\end{tabular}

simulation. The flow stress for the calculated strains, temperature and strain rate were logarithmically interpolated and extrapolated using the available input data. The friction coefficient, $\mu$, used in the simulations was obtained from the strip draw test conducted by Droder [6] and it was assumed not to vary locally with interface temperature and pressure. The interface heat transfer coefficient was assumed to be uniform for the entire surface and the value was selected based on the results published in the literature [10]. Experimental case studies were simulated for four different temperatures for $\mathrm{LDR}=2.3$, Table 2 [6].

\subsection{Results and discussion (round cup)}

\subsubsection{Temperature distribution}

Fig. 4 shows the temperature distribution along the cup wall during forming at different stroke positions, for case A2. During forming, the sheet, which is initially at uniform temperature of $200{ }^{\circ} \mathrm{C}$, comes in contact with punch at room temperature and looses heat. Thus, the region of sheet metal in contact with punch has lower temperature compared to the sheet in contact with the die, as shown in Fig. 4. As the deformation proceeds, the contact with the punch increases, while the contact with the die decreases. As a result, the sheet looses temperature continuously. A small increase in maximum temperature above $200^{\circ} \mathrm{C}$ was observed in the flange due to the heat generation from the plastic work during the process. Large drop in temperature for a very small time period (20s) was observed because $\mathrm{Mg}$ alloy looses heat rapidly due to its high thermal conductivity and low specific heat capacity. Low temperature in the wall and high temperature in the flange (Fig. 4) are essential for warm deep drawing process because, increase in the flow stress due to decrease in temperature enables the cup wall at punch corner to support more stress. The decrease in flow stress with increase in temperature enables the flange material to draw in with less draw force. Thus, any failure by tearing could be postponed and high LDR could be obtained.

Punch temperature plays a critical role in warm forming process as it influences the temperature of cup walls thereby increasing the strength of cup wall compared to flange. Droder [6] found in his experiments that lower punch temperature results in high LDRs. During the process the punch, initially at room temperature, gets warmer. The temperatures observed in experiments and simulations are shown in Fig. 5.

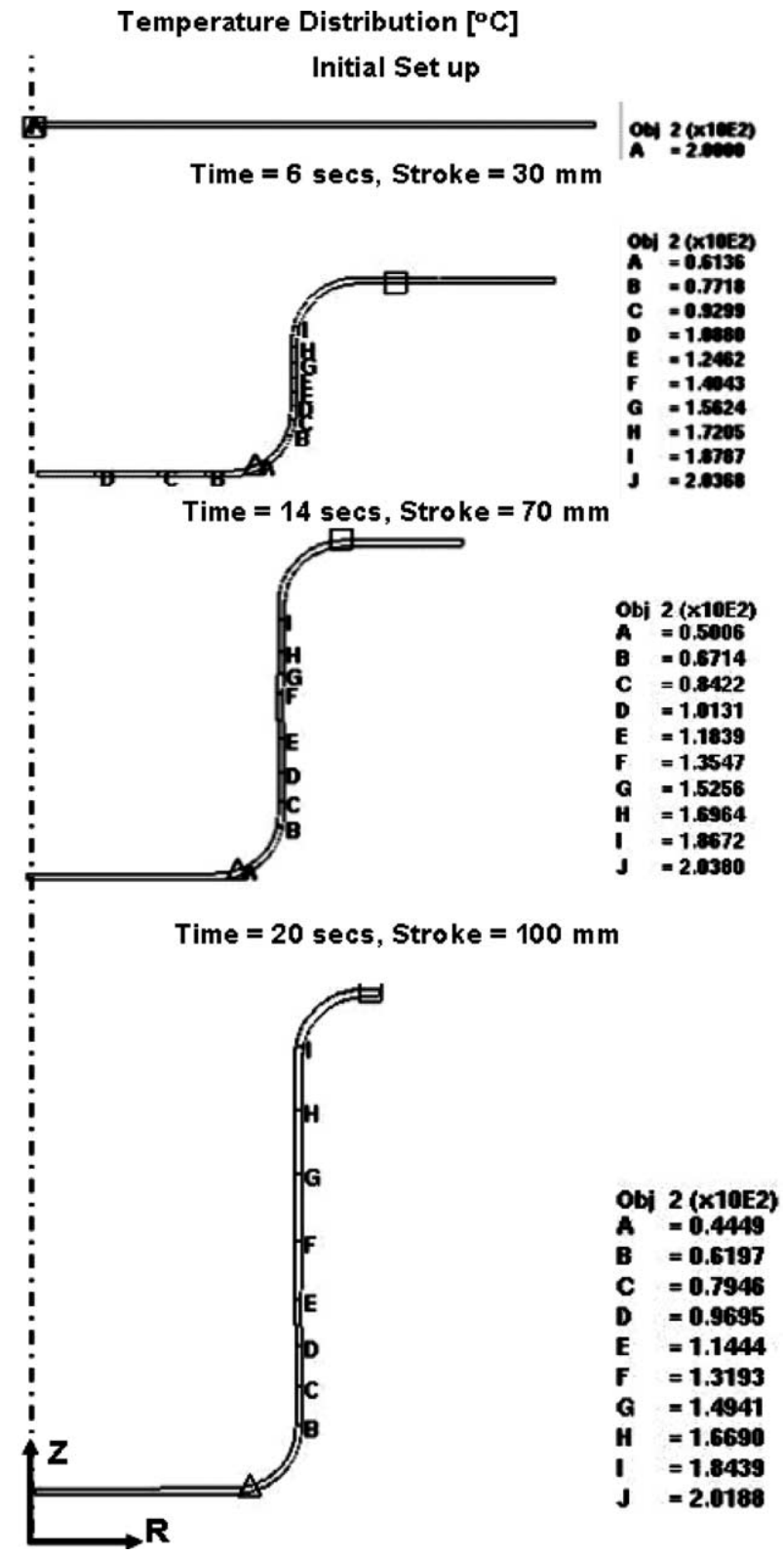

Fig. 4. Temperature variation in the $\mathrm{Mg}$ alloy sheet as predicted by $\mathrm{FE}$ simulation in warm forming of round cup.

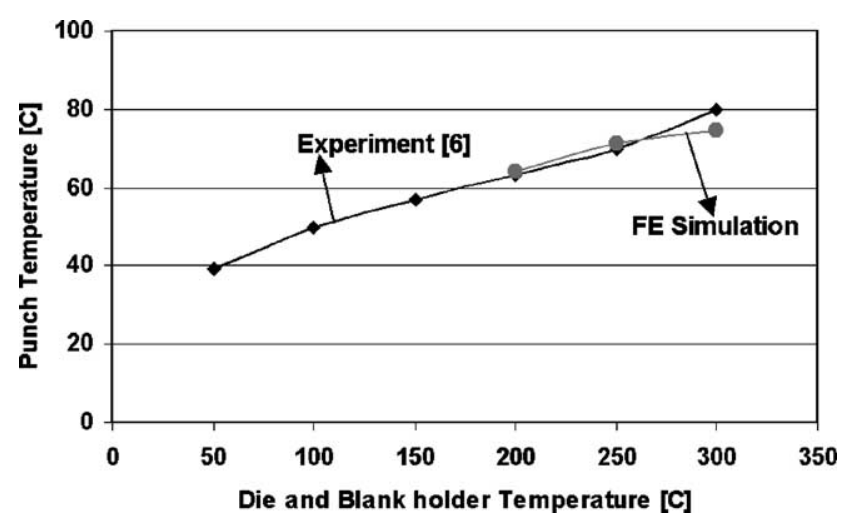

Fig. 5. Comparison of punch temperatures obtained in experiments and simulations. 


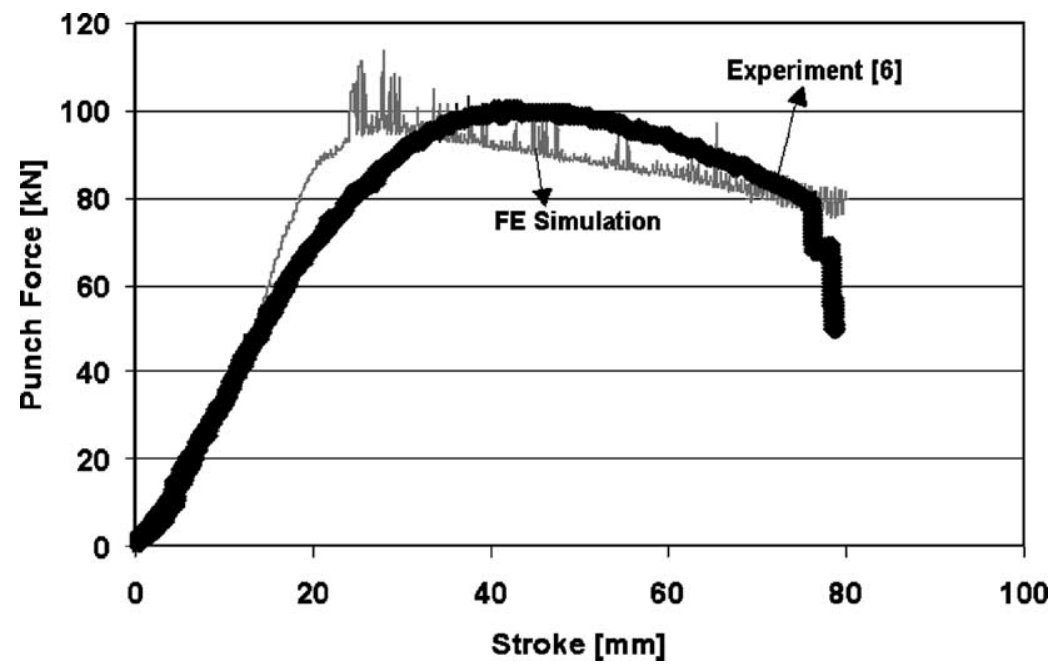

Fig. 6. Punch load obtained from the FE simulation and experiment at forming temperature of $150^{\circ} \mathrm{C}$ for LDR of 2.3 .

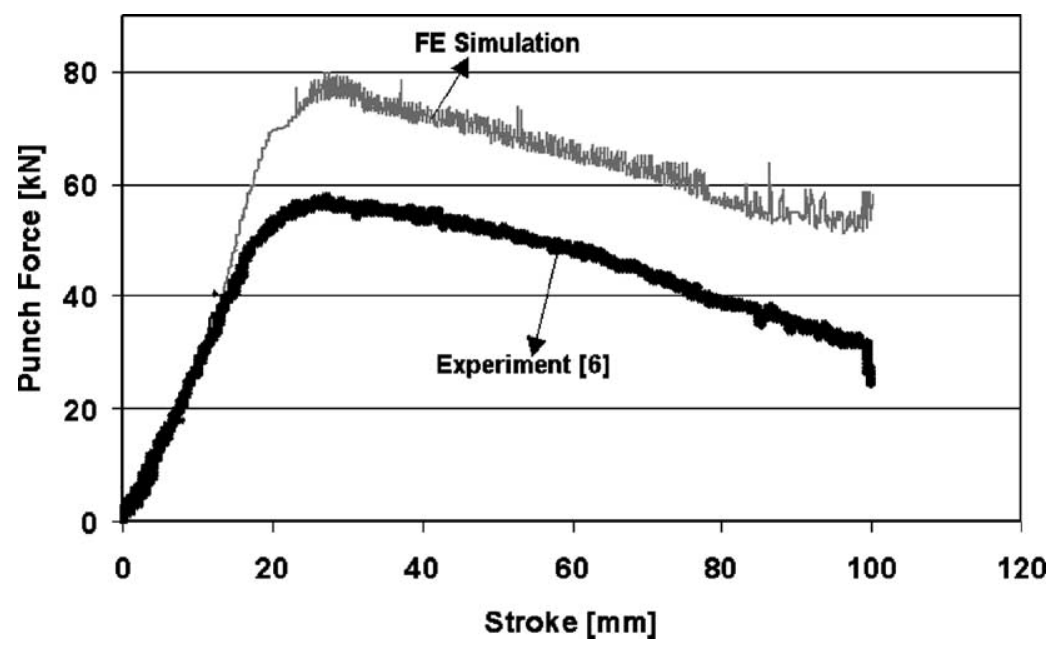

Fig. 7. Punch load obtained from the FE simulation and experiment at forming temperature of $200^{\circ} \mathrm{C}$ for LDR of 2.3 .

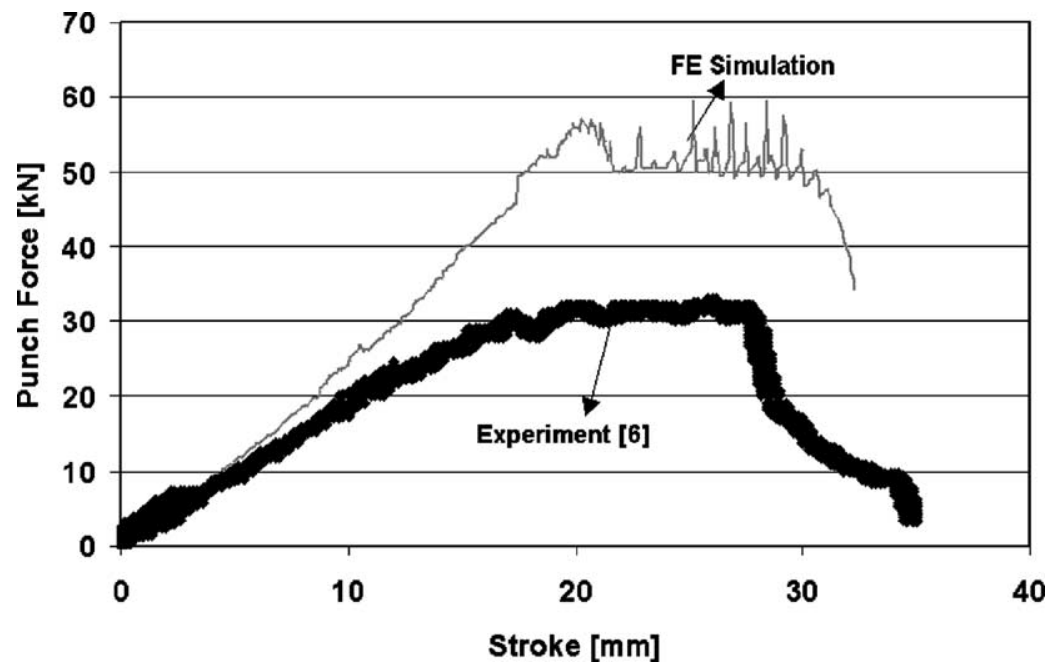

Fig. 8. Punch load obtained from the FE simulation and experiment at forming temperature of $300^{\circ} \mathrm{C}$ for $\mathrm{LDR}$ of 2.3 . 
It should be noted that the punch temperature from the simulation was the maximum obtained in a single cup forming operation, compared to the experiments that included multiple runs. In simulation, multiple runs would further increase the punch temperature depending on the time interval between the runs.

\subsubsection{Punch force}

The punch loads obtained from the simulations for forming temperatures 150,200 and $300^{\circ} \mathrm{C}$ are shown in Figs. 6-8, respectively. The fluctuation in the load-stroke curve observed in the simulation was due to the oscillation of nodes in contact with the punch. The cups were fully drawn for the forming temperatures of 150, 200 and $250{ }^{\circ} \mathrm{C}$. At $300^{\circ} \mathrm{C}$, the cup failed at the stroke of $32 \mathrm{~mm}$. The maximum punch load obtained at all the simulated temperatures for LDR 2.3 was higher than the load obtained in experiment for corresponding temperatures. However, the decrease in punch load with increase in temperature could be predicted in the simulations.

High punch force observed in simulation could be due to: (a) high blank holder force that restrains the material flow; and (b) high shear stress due to interface friction coefficient. The material property for $\mathrm{Mg}$ alloy sheet available from tensile test was limited to low strain rates, strains and temperature up to $200^{\circ} \mathrm{C}$. Beyond this range, logarithmic extrapolation was used. This could be another reason for the over estimation of punch force. Also in the simulation, the material was considered isotropic. However, in magnesium sheets the basal poles are oriented normal to the thickness direction and exhibit normal anisotropy. It should also be noted that in the simulation the von Mises yield criterion was assumed to represent the yield surface of magnesium alloys. However, the best yield criterion that represents yielding in $\mathrm{Mg}$ alloy may still have to be determined.

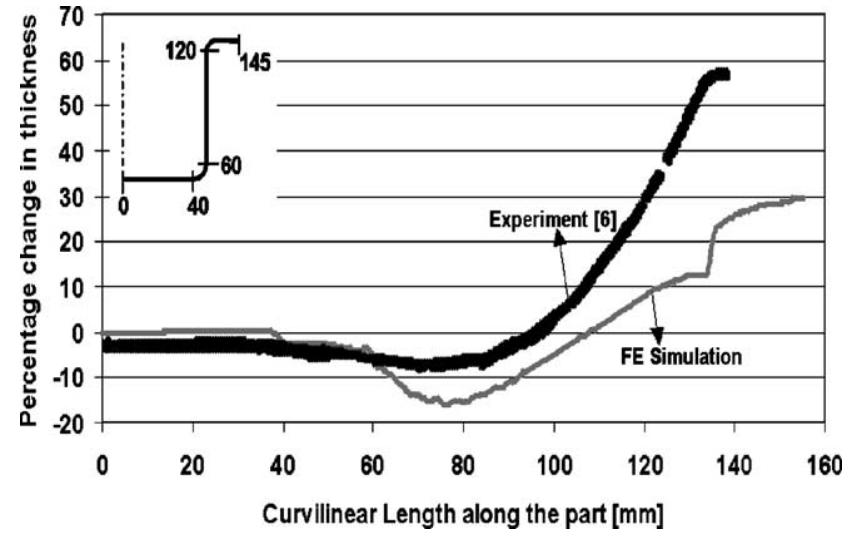

Fig. 9. Percentage thinning distribution from FE simulation and experiment at forming temperature of $200^{\circ} \mathrm{C}$ for LDR of 2.3 .

\subsubsection{Thickness distribution}

Thickness distribution from experiments was available in literature for temperatures of 200 and $250^{\circ} \mathrm{C}$ at LDR of 2.3 . A comparison of the simulation and experimental results is shown in Figs. 9 and 10, respectively. The trend of percentage change in thickness predicted by simulation matches with experiment for forming at 200 and $250^{\circ} \mathrm{C}$. However, less thickening and more thinning has been observed in the simulation as compared to the experiments. Maximum thinning observed in the cup wall for both simulation and experiment is contrary to the conventional stamping where the maximum thinning is observed at punch radius. This could be due to the fact that the strength of the cup wall in warm forming is not uniform as in conventional forming and depends on the temperature distribution in the wall during forming process. As seen in Fig. 4, the temperature was minimum at punch corner radius and increased towards the die corner radius at all stroke positions. Therefore, low yield strength of the material at cup wall compared to the material

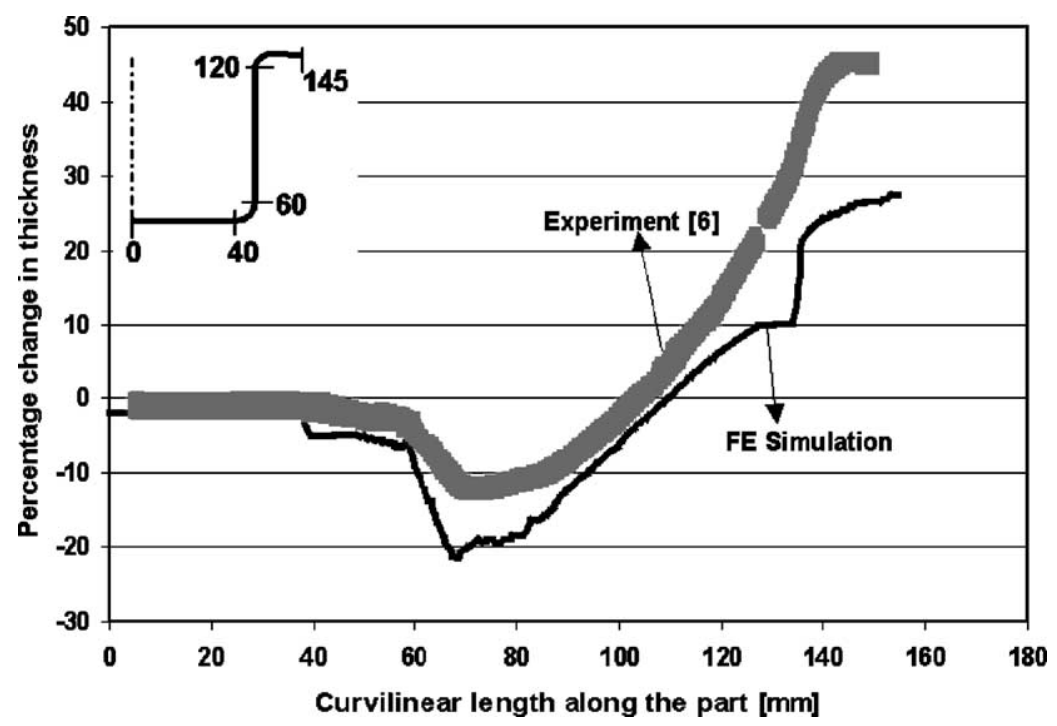

Fig. 10. Percentage thinning distribution from FE simulation and experiment at forming temperature of $250^{\circ} \mathrm{C}$ for LDR of 2.3 . 


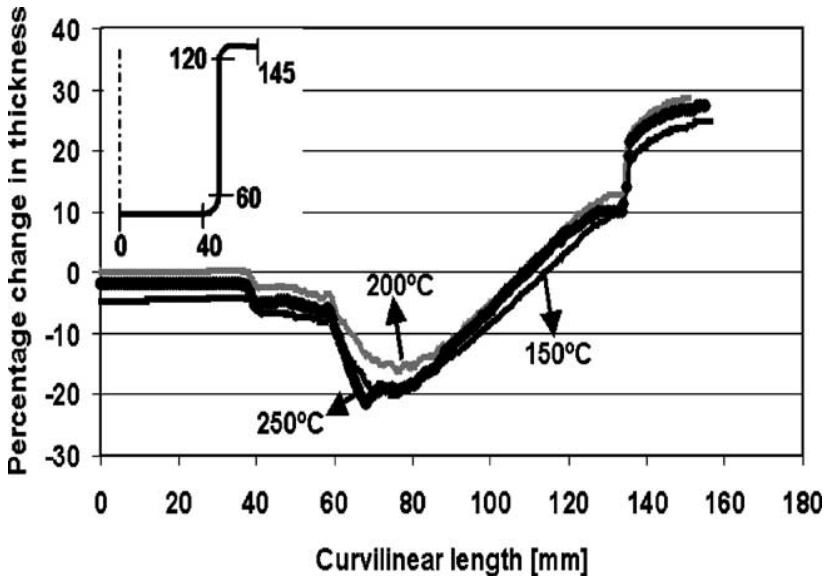

Fig. 11. Percentage thinning distribution from FE simulation at different forming temperatures for LDR of 2.3 .

at punch corner caused thinning in the cup walls rather than at punch corner. Maximum thinning of 22, 15 and $20 \%$ was observed for forming temperatures of 150,200 and $250{ }^{\circ} \mathrm{C}$, respectively (Fig. 11). At $300^{\circ} \mathrm{C}$, localized thinning was observed at a stroke of $32 \mathrm{~mm}$ indicating that the part could fail by tearing (Fig. 12).

More thinning and less thickening was observed in the simulation compared to experiments for the same process parameters. This indicates that the von Mises yield surface used in simulation for determining yielding of the material may overpredict the yield stress in the flange where the radial stresses are tensile and hoop stresses are compressive. Less thinning observed at $200^{\circ} \mathrm{C}$ compared to other forming temperatures indicated that the maximum LDR could be achieved when forming at $200^{\circ} \mathrm{C}$. In experiments, the maximum LDR of 2.5 was obtained when forming at $200^{\circ} \mathrm{C}$ [6]. The comparison of LDRs predicted by simulation and experiment for different forming temperatures is shown in Fig. 13. In simulation, the specimen was considered to fail when thinning exceeds $25 \%$. Localized necking predicted in simulation for different temperatures at high LDRs is shown in Fig. 12. The location of localized thinning obtained in the simulations matched with fracture locations in experiments. Maximum LDR predicted by simulation for differ-

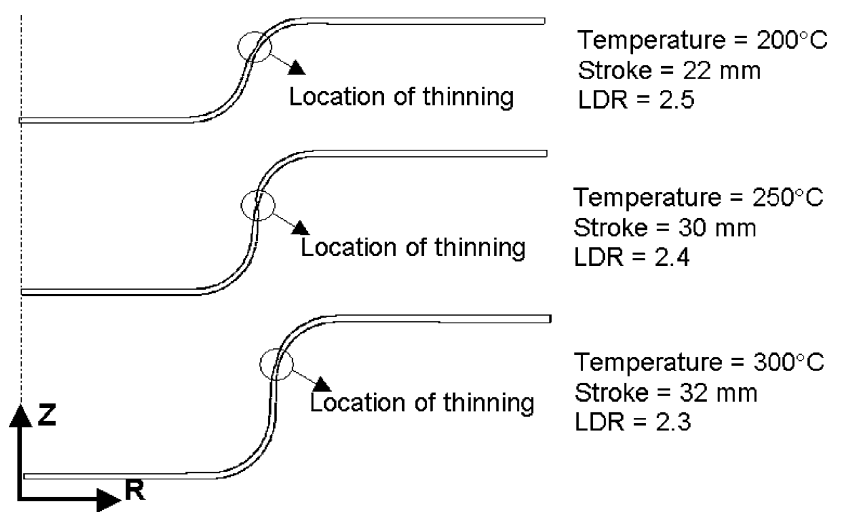

Fig. 12. Locations of maximum thinning predicted by FE simulation.

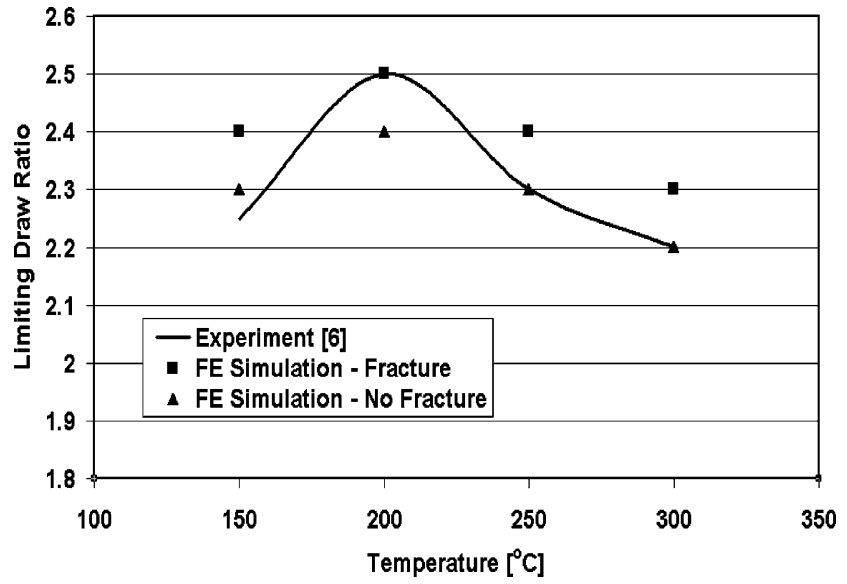

Fig. 13. Comparison of LDR from simulation and experiment at different forming temperatures.

ent forming temperatures was less than that obtained from experiments [6] (Fig. 13).

\section{Warm forming of rectangular pan}

\subsection{FE model}

FE simulations of the $\mathrm{Mg}$ alloy rectangular pan warm forming was conducted using an implicit FE code DEFORM 3D, a coupled thermo-mechanical commercial FEM code, which can be used for non-isothermal simulation. In the analysis, a quarter of the geometry was modeled due to the symmetric boundary conditions (Fig. 14). The sheet was meshed with hexagonal (BRICK) elements with two elements along the thickness to capture the bending strains. These elements have both temperature and displacement as their degrees of freedom to predict both deformation and temperature variation during the process. The dies were meshed with four-noded tetrahedral elements and were considered rigid but non-isothermal. The inputs to simulations are shown in Table 3.

\subsection{Results and discussion (rectangular pan)}

\subsubsection{Temperature distribution}

In rectangular pan forming, the blank was heated in the tooling by clamping the sheet between the die and the blank

Table 3

Process parameters used in simulation ${ }^{\mathrm{a}}$

\begin{tabular}{lc}
\hline Tooling setup & \\
Punch dimension & $220 \mathrm{~mm} \times 110 \mathrm{~mm}$ \\
Punch and die corner radius $(\mathrm{mm})$ & 12 \\
Initial punch temperature $\left({ }^{\circ} \mathrm{C}\right)$ & 150 \\
Die, blank and blank holder temperature $\left({ }^{\circ} \mathrm{C}\right)$ & 200 \\
Initial blank holder pressure $(\mathrm{MPa})$ & 1.6 \\
\hline
\end{tabular}

${ }^{\text {a }}$ Refer Table 1 for mechanical and thermal properties. 


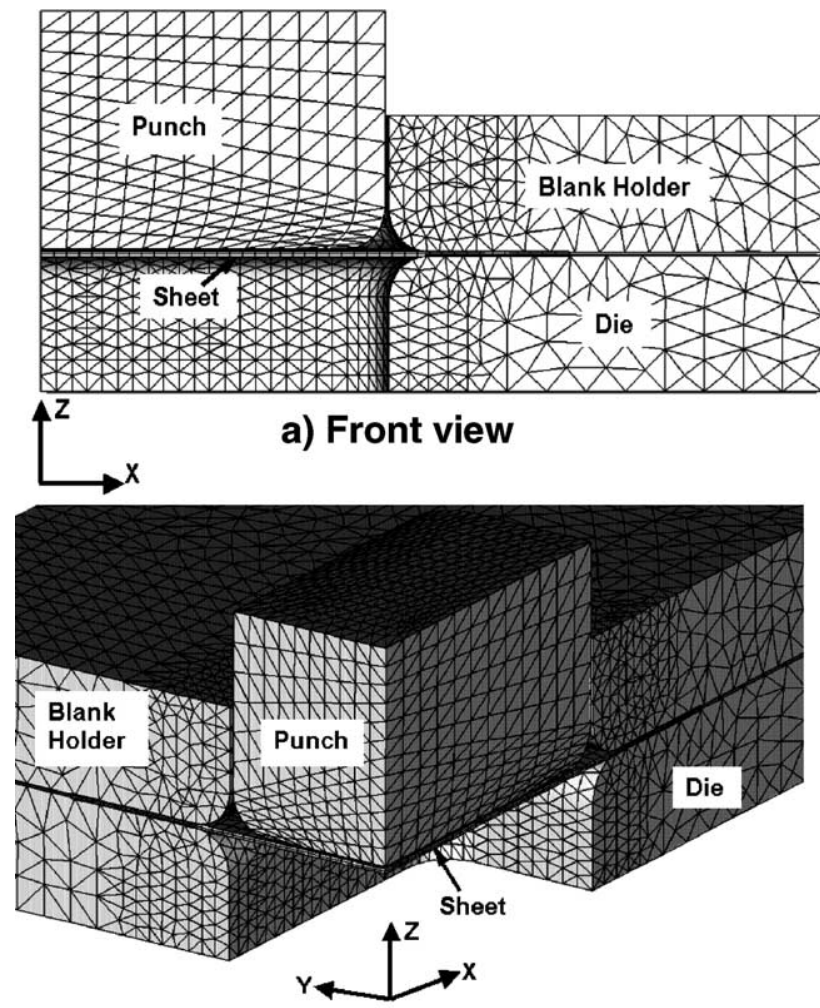

b) Isometric view

Fig. 14. FE model of the rectangular pan warm sheet forming process in DEFORM 3D.

holder maintained at the required temperature [6]. The blank was heated for $2 \mathrm{~s}$ before forming took place, Fig. 15. The region in contact with tooling reached a maximum temperature of $197^{\circ} \mathrm{C}$ compared to the tool temperature of $200^{\circ} \mathrm{C}$. Heating the blank in the tooling provided localized temperature distribution with high temperature in the flange and low temperature in the center of the blank as shown in Fig. 15. This localized temperature distribution is preferable for warm forming process as high temperature in flange allows material to easily draw in with less force. Also, low temperature in cup walls increases the yield stress of the material and thus avoids localized necking.

The temperature distribution in the blank during the forming process is shown in Fig. 16. The blank was formed while

\section{Temperature Distribution $\left[{ }^{\circ} \mathrm{C}\right]$}

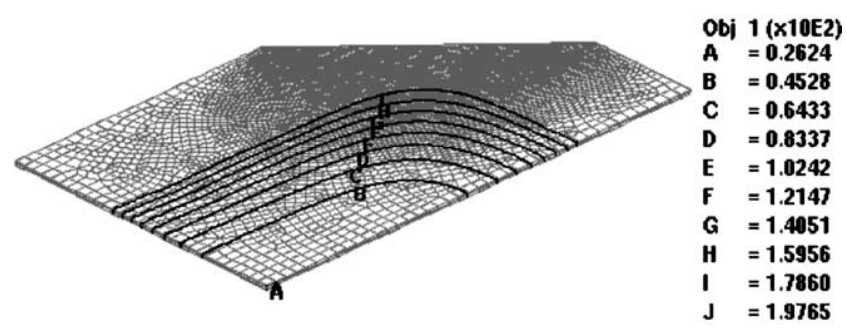

Fig. 15. Temperature distribution in the blank after $2 \mathrm{~s}$ when heated inside tooling.

\section{Temperature Distribution $\left[{ }^{\circ} \mathrm{C}\right]$}
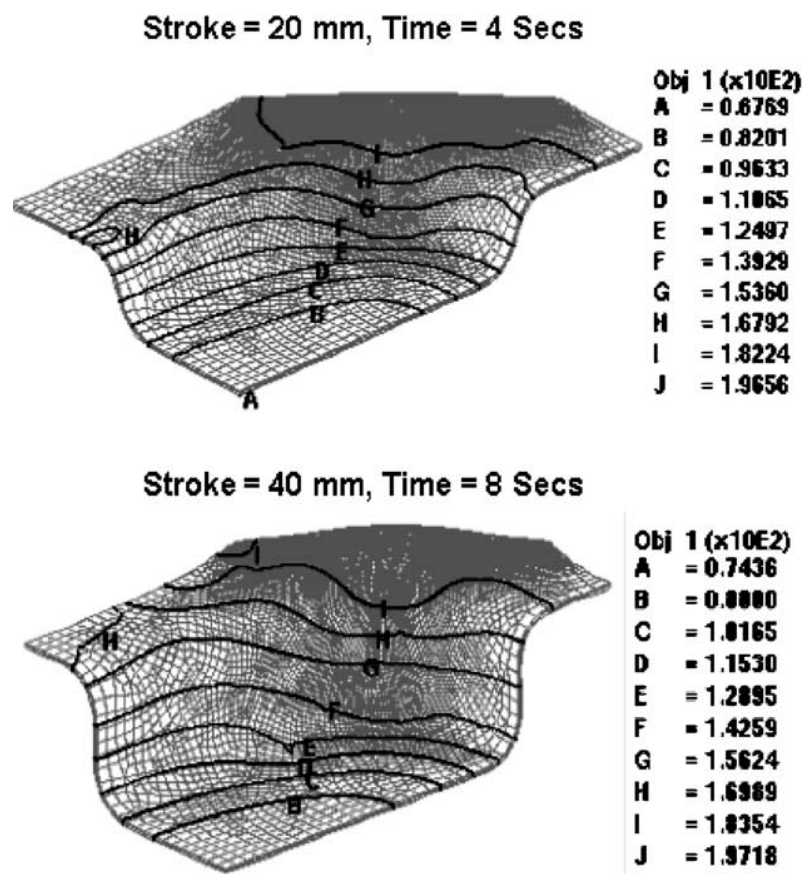

Stroke $=55 \mathrm{~mm}$, Time $=11$ Secs

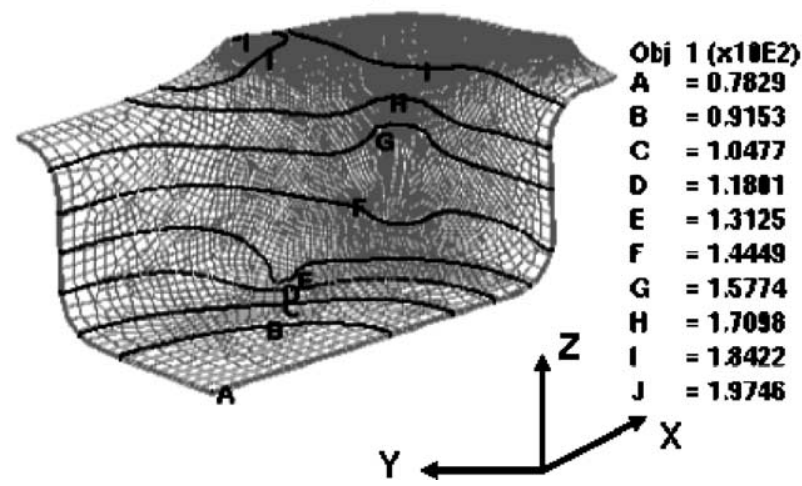

Fig. 16. Temperature variation in the Mg alloy sheet as predicted by FE simulation in warm forming of rectangular pan.

the punch was maintained at $150^{\circ} \mathrm{C}$. Thus, the minimum blank temperature continues to increase while forming. The wall and the flange along the length of the pan have low temperature compared to wall and flange at the corners and width of the pan. Large drop in temperature along the length of the pan was due to large surface area for heat transfer to surroundings and to the punch. The temperature was maximum at the sheet corner due to less surface area for convection and small temperature gradient for heat conduction within the sheet. The temperature distribution obtained in the simulation cannot be compared with experimental data, as temperature distribution in the sheet during the forming process is not available in the literature.

High temperature predicted in corners compared to straight edges is preferable for warm forming process. Material can be easily drawn from high temperature locations 


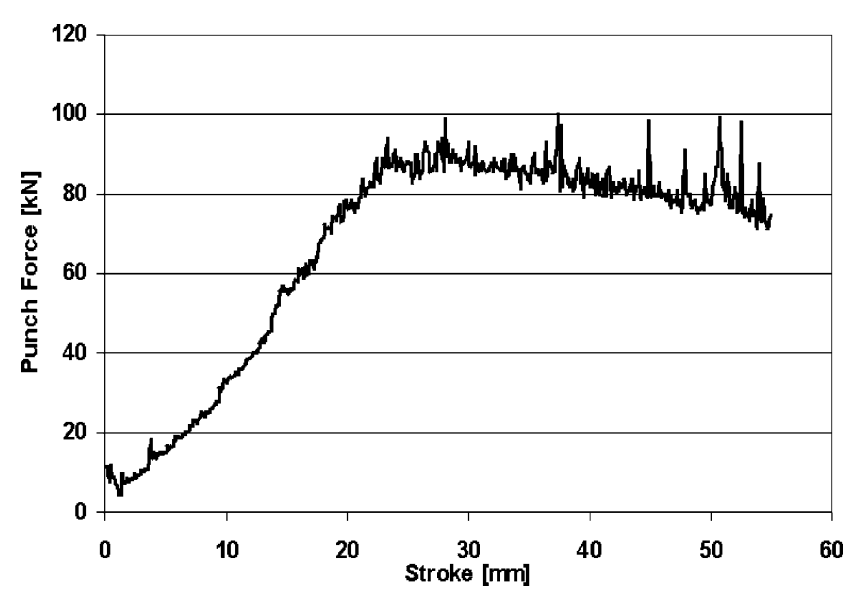

Fig. 17. Punch load obtained from the FE simulation for forming rectangular pan at $200^{\circ} \mathrm{C}$.

(corners) compared to low temperature location (straight edges) as flow stress increases with decrease in temperature. Thus, fracture at the corners could be eliminated and large draw depth can be obtained. Doege et al. [3] concluded from their experiments that a rectangular pan of maximum $98 \mathrm{~mm}$ deep could be drawn by varying the temperature distribution locally in the flange. High temperature at the locations of maximum strains such as corners and low temperature in straight edges would allow the material to flow freely from corners. Thus the occurrence of wrinkle and rapid thinning can be postponed and high part depth can be obtained.

\subsubsection{Punch load}

Fig. 17 shows the punch force obtained from simulation. A maximum forming load of $92 \mathrm{kN}$ was obtained in the simulation. The load-stroke curve from the experiment was not available and hence a direct comparison could not be made.

\subsubsection{Thickness distribution}

The thickness distribution from the experiment and simulation is shown in Fig. 18. The trend predicted by simulation was similar to that from experiment. However, a maximum thinning of $30 \%$ was observed in the simulation as compared to $10 \%$ in experiment. Minimum thickness was observed in

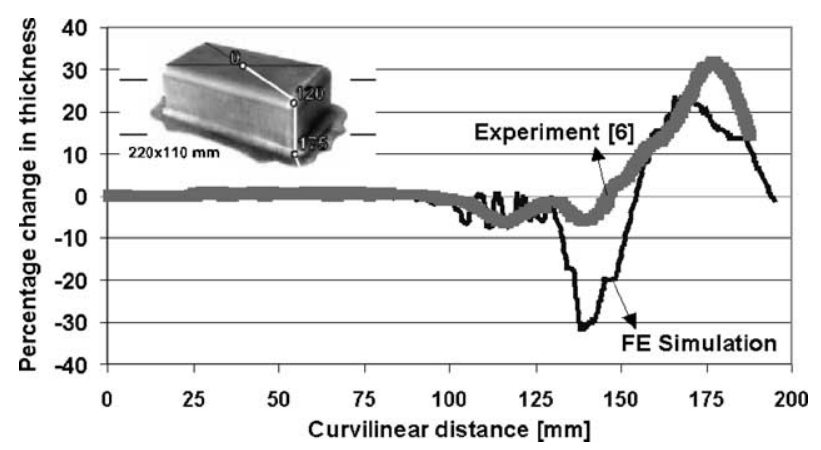

Fig. 18. Comparison of thickness distribution obtained from FE simulation and experiment for rectangular pan.

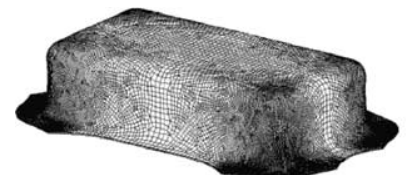

(a) Isometric view

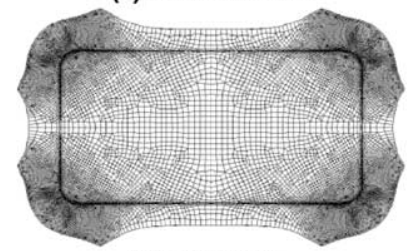

(b) Top view

Simulation
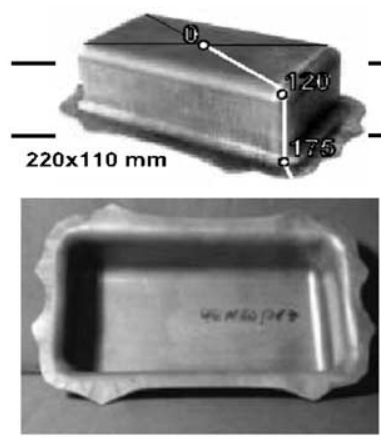

Experiment
Fig. 19. Comparison of drawn shape of rectangular pan obtained in experiment and simulation.

the corner walls because of the restricted material flow from the flange corner compared to the material flow from straight edges. Thus, a large flange was seen in the simulated drawn pan compared to the experiments as shown in Fig. 19. This difference in material flow could be attributed either due to high friction force and/or low temperature in the flange corners as compared to experiment. It should also be noted that the flow stress available from tensile test was limited to small strains at low strain rates. Therefore, in the simulation the flow stress for high strains and high strain rates were extrapolated. These values have been probably overestimated. Thus, more restraining force to draw the material from the flange had resulted in localized thinning of $30 \%$ in the simulation.

\section{Conclusions and future work}

FE analysis has been used to simulate warm forming process of magnesium alloys. Forming of two parts, a round cup and a rectangular pan, was simulated using commercial FE codes DEFORM 2D and 3D, respectively. Simulations were conducted for the experimental cases published by Droder [6], and Doege et al. [3]. The major conclusions drawn from this study are as follows.

1. The forming load predicted by simulation for round cup and rectangular pan overestimated the experimental results. However, the trend predicted by simulation matches well with experiment. Higher punch force in the simulation could be due to the high frictional shear stress at interface. Coulomb friction coefficient of $\mu=0.1$ was used in the simulation. Also the material properties extrapolated at high strains and high temperatures from known values could be overestimated in the calculation. von Mises yield criteria was used in simulation to describe the yield surface of $\mathrm{Mg}$ alloy sheets. However, the yield surface for $\mathrm{Mg}$ alloy sheets like aluminum alloy sheets may not strictly follow the von Mises yield criterion.

2. In the warm sheet forming of round cup and rectangular pan, the maximum thinning and tearing was observed 
at the cup wall in simulation and experiment. This is contrary to the observations in conventional stamping where the thinning occurs in the punch corner radius. This could be due to the fact that the cup walls in warm forming were at high temperature compared to punch corners, thus, the yield strength of material in cup wall was low compared to punch corner radius.

3. The location of maximum thinning and localized thinning observed in the simulation for round cup and rectangular pan match with experiment. However, the predicted thinning values were larger than the experimental data. Excessive thinning observed in the simulation could be due to high process loads observed in simulation as compared to experiment.

4. LDR predicted by simulations for round cup for different forming temperatures were lower compared to the experimental results.

5. Thermo-elastic-visco-plastic FEM code used in this study could successfully capture the deformation modes and the specific characteristics of the warm sheet forming process. However, to improve the accuracy and reliability, the following need to be addressed:

(a) Better understanding of the numerical representation of the yield surface of $\mathrm{Mg}$ alloys.

(b) New material models in the FEM code that can better handle the properties of $\mathrm{Mg}$ alloys at high strain rates and temperature with capabilities for strain softening characteristics due to their viscous effects.

\section{Acknowledgements}

Prof. E. Doege, Dr. K. Droder and their associates at IFUM, Technical University of Hanover, provided the ex- perimental data used in this study. The authors gratefully acknowledge this technical support.

\section{References}

[1] H. Fredrich, S. Schumann, Research for a new age of magnesium in the automotive industry, J. Mater. Process. Technol. 117 (2001) 276-281.

[2] E.F. Emley, Principles of Magnesium Technology, Pergamon Press, Oxford, 1966.

[3] E. Doege, K. Droder, Sheet metal formability of magnesium wrought alloys-formability and process technology, J. Mater. Process. Technol. 115 (2001) 14-19.

[4] E. Doege, L.E. Elend, F. Meiners, Comparative study of massive and sheet light weight components formed of different light weight alloys for automobile applications, in: Proceedings of the ISATA, 2000, pp. 87-94.

[5] E. Doege, K. Droder, Processing of magnesium sheet metals by deep drawing and stretch forming, Mater. Techn. 78 (1997) 19-23.

[6] K. Droder, Analysis on forming of thin magnesium sheets, Ph.D. Dissertation, IFUM, University of Hanover, 1999 (in German).

[7] E. Doege, W. Sebastian, K. Droder, G. Kurtz, Increased formability of $\mathrm{Mg}$-sheets using temperature controlled deep drawing tools, in: M.Y. Demeri (Ed.), Innovations in Processing and Manufacturing of Sheet Materials, The Minerals, Metals and Materials Society, 2001, pp. 53-60.

[8] S. Ghosh, N. Kikuchi, Finite element formulation for simulation of hot sheet metal forming process, Int. J. Eng. Sci. 26 (2) (1988) 143-161.

[9] P.J. Bolt, R.J. Werkhoven, A.H. van de Boogaard, Effect of elevated temperature on the drawability of aluminum sheet components, in: Proceedings of the ESAFORM, 2001, pp. 769-772.

[10] S.L. Semiatin, E.W. Collings, V.E. Wood, T. Altan, Determination of the interface heat transfer coefficient for non-isothermal bulk forming process, J. Eng. Ind. 109 (1987) 49-57. 